\title{
Estimation of the refractivity gradient from measured essential climate variables in Iyamho-Auchi, Edo State, South-South Region of Nigeria
}

\author{
Kingsley Eghonghon Ukhurebor ${ }^{1}$, Wilson Nwankwo ${ }^{2}$ \\ ${ }^{1}$ Climatic/Environmental/Telecommunication Physics Unit, Department of Physics, Edo University Iyamho, Nigeria \\ ${ }^{2}$ Software Engineering/Cyber Physical Lab, Department of Computer Science, Edo University Iyamho, Nigeria
}

\begin{tabular}{l} 
Article Info \\
\hline Article history: \\
Received Nov 2, 2019 \\
Revised Dec 10, 2019 \\
Accepted Jan 16, 2020 \\
\hline
\end{tabular}

\section{Keywords:}

Atmospheric pressure

Radio waves

Refractivity

Relative humidity

Temperature

\begin{abstract}
Meteorological variables are crucial constituents in the estimation of refractivity disseminations and the uncharacteristic radio wave propagation situations of the troposphere as a result of their impact on radio wave communication relations over the atmosphere. In this study the measurement and assessment of air temperature, relative humidity and atmospheric pressure was carried out for a period of one year; 2018, so as to estimate the refractivity gradient over Iyamho-Auchi, Edo State, Nigeria using a self-implemented inexpensive portable meteorological monitoring device. The measurements of the essential climate variables were done at the administrative building of Edo University Iyamho by placing the meteorological monitoring device on a fixed position. The results show that the monthly estimated refractivity gradient values which would be useful in the prediction of the local radio propagation range from $-20.00 \mathrm{~N}$-units $/ \mathrm{km}$ to $-190.00 \mathrm{~N}$-units $/ \mathrm{km}$ with an average value of $-60.67 \mathrm{~N}$-units $/ \mathrm{km}$ for the period under consideration. The findings also show that the months with limited relative humidity have greater refractivity gradient values compared to the ones with higher relative humidity. It was also observed from the results that the measured essential climate variables were having significant impacts on the estimated refractivity gradient during all the months in 2018, and these impacts were more noticeable in the months with higher relative humidity compared with the months that were having limited relative humidity.
\end{abstract}

Copyright $\odot 2020$ Institute of Advanced Engineering and Science. All rights reserved.

\section{Corresponding Author:}

Kingsley Eghonghon Ukhurebor,

Climatic/Environmental/Telecommunication Unit,

Department of Physics, Edo University Iyamho,

P.M.B. 04 Auchi, Edo State, Nigeria.

Email: ukhurebor.kingsley@edouniversity.edu.ng

\section{INTRODUCTION}

Meteorological variables are very important in the derivation of refractivity disseminations and the local radio wave propagation situations of the troposphere, as a result of their effect on radio wave communication links in the troposphere [1-14]. Refractivity distributions studies play a momentous role in dealing effectively with the complications that arise as a result of the uncharacteristic radio wave propagation and unexpected path loss that disturbs the performance of radio signals from cellular network, navigation and surveillance systems.

Most essential climate variables like air temperature, relative humidity and atmospheric pressure need to be adequately accessed so as to have better local radio propagation conditions, which would enhance the quality of services of cellular network service providers, navigation and radar system designers. 
Accordingly, accessing these essential climate variables will undoubtedly assist in providing a reliable meteorological blueprint on local radio propagation situations that will assist cellular network service providers, navigation and radar system designers in improving their quality of services [1-3, 15-18].

According to [1-3], refractivity distribution studies are imperative in radio signal systems. Consequently, in order to deal with the complications that arise as a result of inconsistent radio wave propagation and the unexpected path loss that disturbs their performance. These unexpected radio wave propagations could cause severe impacts to the extent of complete interruption of the communication between the transmitters and the receivers or even make radar to wholly miss its projected target. Therefore, it is essential for the to take into account the variation of the propagating radio wave resulting from the instabilities in the refractivity distribution [1-3, 15-18]. Refractivity gradient as well as other refractivity statistics would make available some of the most needed description of the possible manifestation of refractivity related impact required for local radio wave estimation procedures [1-14]. Since the radio wave communication links are exaggerated by meteorological variables. Therefore, to have an improved communication link for radio wave, the transmission intermediate need to be painstaking [1-5]. The attitude and phase scintillations, absorption, scattering of radio wave network signals and several other complex mechanisms that arise in the troposphere are instigated by the haphazard variations in the surface and vertical refractivity which can cause transmission signals lost and co-channel interference. The impact of interference as a consequence of refractivity alteration in the troposphere is higher in the humid climate compared to that from moderate climate regions as a result of the existence of high intensity humid precipitation [3, 4]. Some frequently used procedures of denoting the International Telecommunications Union recommendation (ITU-R) which are currently being used in setting up of broadcasting services for frequencies $\geq 30 \mathrm{MHz}$ are obtained from measurements carried out in most temperate climate regions of the world like Europe, Asia and North America. Although, the sub-Sahara African climate is not the same with these temperate climate regions own, these methods can still be used for the planning of radio wave propagation services due to the scarcity of accurate meteorological data from these regions [1-14]. To control the characteristics of a radio channel, refractivity data are often desirable. The atmospheric refractivity is very significant for the deduction of some propagation impacts.

Several studies have revealed that the variation in refractivity in the lower atmosphere is a function of some essential climate variables and it varies in space and due to the physical procedures, that take place in the atmosphere [1-14]. This is often not too easy to describe in a deterministic manner, as such it had to be considered in most cases as random with its probabilistic characteristics. The countless phenomena in the wave propagation such as fading of electromagnetic waves ducting, refraction, range, scintillation, and elevation errors in radar attainment are as a result of refractivity $[3,14]$. Refractive appearances are very important in the development and designing of terrestrial communication systems, due to multi-path fading and interference due to trans-horizon propagation.

Recent studies on refractivity effects uses both the experimental results gotten from in situ measurements and the computational methods in simulating the refractivity related propagation impacts $[3,14]$. The results from these studies have assisted telecommunication network, navigation and surveillance systems in mitigating the complications that as a result of the uncharacteristic radio wave propagation and unexpected path loss that disturbs their performance. In this study the measurement and assessment of some essential climate variables (air temperature, relative humidity and atmospheric pressure) using a self-implemented inexpensive portable meteorological monitoring device was carried out for a period of one year; 2018. These measured essential climate variables were used to estimate and analyse the refractivity gradient over Iyamho-Auchi, Edo State, Nigeria. Exclusively, it is expected that results which are to be obtained from the study which is one of the most recent studies on the rapport between some essential climate variables and refractivity statistics specifically in Iyamho-Auchi, Edo State, South-South, Nigeria would be of significant assistance to the management of radio systems in enhancing the quality of radio signals.

\section{MATERIALS AND METHODS}

\subsection{A Self-implemented meteorological monitoring device}

The meteorological monitoring device was implemented in such a way that it could be rummage-sale remotely for the measurements of air temperature $\left({ }^{\circ} \mathrm{C}\right)$, relative humidity $(\%)$, atmospheric pressure (mbar), wind speed $(\mathrm{m} / \mathrm{s}$ ) and light intensity (lux). The readings from the device are displayed on the user-friendly LCD display in numerical digital values and could as well be sent to computer through the programmed micro SD card or/and through the serial port (the Arduino SD Card Module).

In this implementation a full set of climatic variables can be acquired within few seconds which is relatively fast compare to some other meteorological monitoring devices that require meteorological 
variables to be logged every hour or thereabout. However, the user has the choice of selecting the frequency of climatic variables that will be measured, logged, stored and displayed. The acquired respective values of the climatic variables are shown on the LCD. In addition, the variables for each day are hoarded on the micro SD card in Microsoft Excel setup on a separate file with each file created with a file name that corresponds to the period when the such data were acquired. The user also has the choice to stop the variables acquisition procedure at any time by intruding the routine. After the implementation processes were completed testing was carried out. It was found that the device was working properly.

According to [19-20], such self-implemented meteorological device needs to undertake recalibration and comparison. As such for validation purposes, measurements of the essential climate variables were carried out between 1st to 8th November, 2016 at the Centre for Atmospheric Research (CAR), Ayangba, Kogi State Nigeria during the initial stage. The results from the recalibration and comparison affirmed that the implemented device works with minimum error. Details of the construction and implementation of the device including the validation results are contained in [21].

\subsection{Location of measurements}

The measurements of the essential climate variables were carried out at the administrative block of Edo University Iyamho-Auchi, Edo State, South-South, Nigeria located around Latitude $7.07^{\circ} \mathrm{N}$ and Longitude $6.27^{\circ} \mathrm{E}$ of the Greenwich Meridian. The area experiences the humid tropical climate, which is categorized by wet and dry seasons. The vegetation is that of the Savannah, with typical open grassland and limited dispersed fire-resistant trees. The topography is comparatively undulating and it slants from the northern part to the south $[1-3,22]$. Figure 1 shows the aerial view of the study area from google earth map.

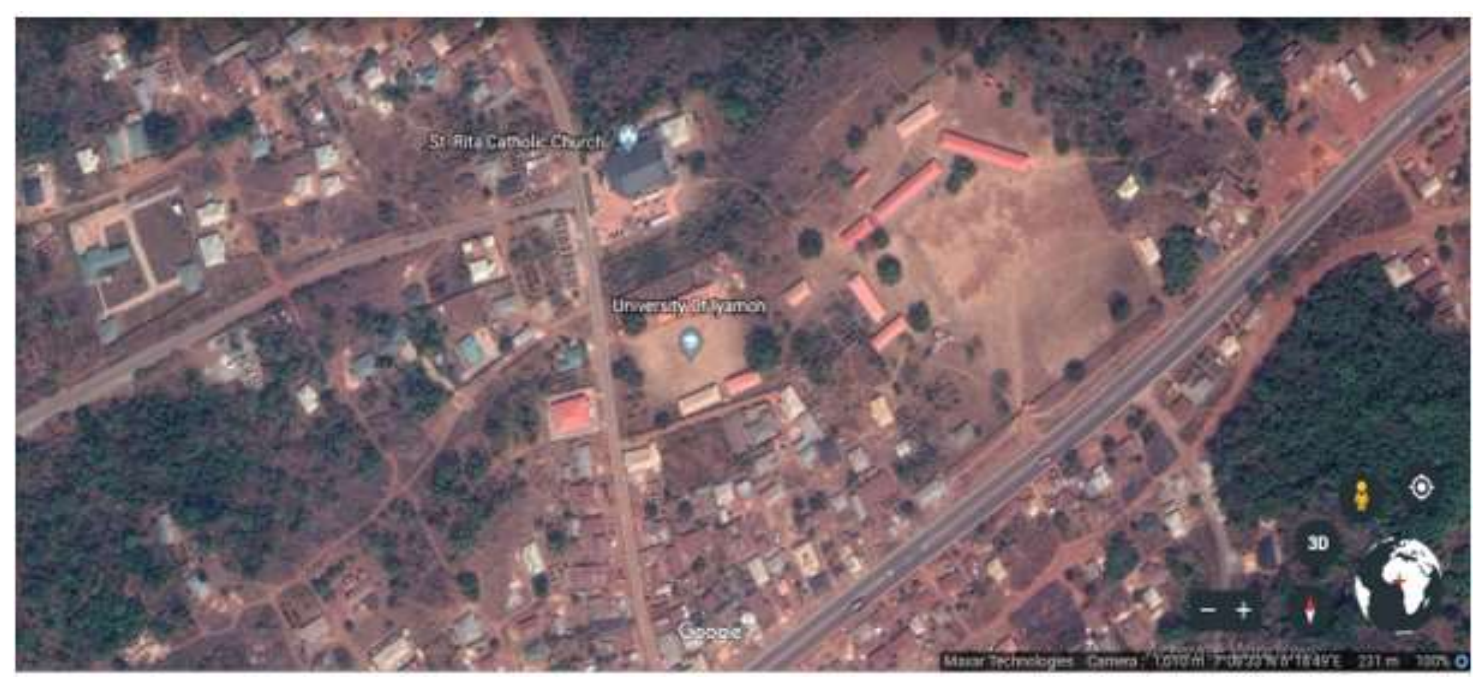

Figure 1. Aerial view of Iyamho-Auchi, Edo State, Nigeria (sourch: Google Earth Map)

\subsection{Method of measurements}

The measurements of the essential climate variables were done at the administrative building of Edo University Iyamho with an elevation of about $188 \mathrm{~m}$ height above sea level by placing the meteorological monitoring device on a fixed position for continuous measurements. Although, the meteorological monitoring device measures five meteorological variables as stated earlier, only the daily records of three essential climate variables which include air temperature $\left({ }^{\circ} \mathrm{C}\right)$, relative humidity (\%) and atmospheric pressure (mbars) were used for this study. The records cover twenty-four hours each day from 00 hour to 2300 hours local time at intervals of one hour of which the mean values from each day are then copied from the micro SD card to the computer from the device. The measurements of the essential climate variables were made for a period of one year (January to December, 2018). The mean monthly measured values that were used for the analysis in this study are contained in Table 1. The mean values are $25.46{ }^{\circ} \mathrm{C}, 73.08 \%$ and 1004.56 mbar for air temperature, relative humidity and atmospheric pressure respectively. 
Table 1. Average measured meteorological variable for 2018

\begin{tabular}{lccc}
\hline \multicolumn{1}{c}{ Month } & Average Air Temperature $\left({ }^{\circ} \mathrm{C}\right)$ & Average Relative Humidity $(\%)$ & Average Atmospheric Pressure $(\mathrm{mbars})$ \\
\hline January & 28.20 & 42.70 & 1001.70 \\
February & 31.80 & 48.20 & 1002.50 \\
March & 30.10 & 68.70 & 1004.60 \\
April & 29.30 & 85.20 & 1007.10 \\
May & 28.40 & 92.10 & 1005.70 \\
June & 26.30 & 92.40 & 1005.90 \\
July & 25.00 & 95.30 & 1004.70 \\
August & 16.60 & 78.60 & 1003.90 \\
September & 25.50 & 78.40 & 1005.40 \\
October & 25.70 & 68.90 & 1005.60 \\
November & 27.80 & 68.20 & 1004.70 \\
December & 26.50 & 58.30 & 1002.90 \\
Mean & 25.46 & 73.08 & 1004.56 \\
\hline
\end{tabular}

\section{THEORETICAL BACKGROUND FOR REFRACTIVITY ESTIMATION}

It has been established that the electromagnetic waves which pass through the atmosphere bends, as a consequence of the different layers of the atmosphere and its permittivity, otherwise it would have travel in a straight path if it was homogeneous. This is instigated by the spatial distribution of the refractive index of the air which causes contending effects [3, 14]. The atmosphere's refractive index, $n$ and the relative permittivity, $\varepsilon_{r}$ are connected mathematically with:

$$
n^{2}=\varepsilon_{r}
$$

Since, $n \approx 1$ and the variations are infinitesimal. An appropriate parameter that could be used when modelling the change of the refractivity of the atmosphere (atmospheric refractive index) $N$, which can be defined mathematically according to $[3,11,14]$ as:

$$
N=(n-1) \times 10^{6}
$$

$N$ and the essential climate variables such as the air temperature, atmospheric pressure and vapour pressure can be connected mathematically by;

$$
N=\frac{77.60}{T}\left(P+4810 \frac{e}{T}\right)
$$

Hence, $N$ according to the recommendation International Telecommunications Union, 2015 [11], can be expressed mathematically as:

$$
N=77.60 \frac{P}{T}+\left(3.73 \times 10^{5} \frac{e}{T^{2}}\right)
$$

The refractivity of the troposphere can be alienated into two portions, namely; the dry portion, $N_{d}$ and the wet portion, $N_{w}$. The dry portion contributes about $70 \%$ of the total refractivity in the troposphere. This dry portion has a direct proportionality with the density of the gas molecules and changes with their distribution. It is usually stable and can be approximated from the measured air temperature and atmospheric pressure with an accuracy of about $20 \%$ using:

$$
N_{d}=77.60 \frac{P}{T}
$$

Where $P$ is barometric pressure (mbars) and $T$ is absolute temperature in Kelvin [1-3, 6].

While, the wet portion which is a consequence of the polar nature of water molecules and it contributes the main change in the refractivity in the troposphere and can be approximated according to $[1-3,6]$ using: 


$$
N_{w}=3.73 \times 10^{5} \frac{e}{T^{2}}
$$

Where $e$ is partial pressure of water vapour (mbars) as earlier defined as:

$$
e=\frac{R H}{100} \times e_{s}
$$

Where $R H$ is the relative humidity; $\%$ and $e_{s}$ is the saturated vapour pressure (mbars) which is expressed by:

$$
e_{s}=6.11 \times 10^{\frac{17.27(T-273.15)}{T-35.85}}
$$

Since $h$ is the height of a ray directly above the earth's surface. Hence, the radius of the ray of curvature $r$, and the vertical gradient of $N$ which is denoted by $\frac{\partial N}{\partial h}$.

Therefore, the horizontal angle of the path to a given point which is denoted by $\theta$ can be written as:

$$
\frac{1}{r}=\frac{1}{N}\left(\frac{\partial N}{\partial h}\right) \cos \theta
$$

According to [9], $r$ could be linked to the comparative earth radius which is denoted $R$ in place of the refractive index gradient as:

$$
\frac{r}{R}=k
$$

Where $k$ is the effective earth radius factor which can then be mathematically expressed as:

$$
k=\frac{1}{1+R\left(\frac{\partial N}{\partial h}\right)}
$$

Hence, the (11) can also be mathematically expressed in place of refractivity $N$, since $R \approx 6370 \mathrm{~km}$ :

$$
k \approx \frac{\frac{1}{1+\left(\frac{\partial N}{\partial h}\right)}}{157}
$$

The $k$-factor could be rummage-sale for categorizing the refractive conditions accordingly [5].

Around the earth's surface, $\frac{\partial N}{\partial h} \approx-39 \mathrm{~N}$-units/km, and $k \approx 1.33$; in this state it is known as normal refraction or standard atmosphere. Here, radio signals are conveyed laterally on a straight-line route on the earth's surface and move into space unrestricted. If, $1.33 \succ k \succ 0$, we would have what is known as sub-refraction and this suggests that the radio waves are broadcast uncharacteristically away from the earth's surface. But when $\infty \succ k \succ 1.33$ we would have what is known as super-refraction and this suggests that the radio wave signals propagate intermittently towards the earth's surface and this will outspread the radio horizon as well as upsurge path clearance. Thus, giving intermittent huge ranges above the line of view as a result of multiple reflections. However, if $-\infty \prec k \prec 0$ there would be what is known as ducting which could make the radio waves to curve downwards with a curvature that is greater than that of the earth. The radio 
signals can become stuck between a layer in the troposphere and the surface duct (that is the earth's or sea's surface) or flanked by two layers in the troposphere which is the elevated duct. In this wave guide-like propagation, very high radio signal strengths could be obtained at a very long range which is far above the line of view [1-14].

\section{DISCUSSION OF RESULTS}

In this study, the analysis was carried out procedurally through the estimation of refractivity gradient from the measured essential climate variables imploring (1) to (12) accordingly. Some statistical analysis was also done so as to determine their variation between these measured essential climate variables and the estimated of refractivity gradient. Comparisons of the various measured essential climate variables and the estimated refractivity gradient were also respectively done graphically. The mean monthly estimated refractivity gradient is contained in Table 2 . The values range from $-20.00 \mathrm{~N}$-units $/ \mathrm{km}$ to $-190.00 \mathrm{~N}$-units $/ \mathrm{km}$ with an average value of $-60.67 \mathrm{~N}$-units $/ \mathrm{km}$ for the period under deliberation. These estimated monthly refractivity gradient values for 2018 are is in conformity with the values obtained from results of $[4,6,7,10]$.

In Figure 2, the monthly estimated refractivity gradient values for 2018 which were obtained accordingly is presented. From the Figure it was observed that the months with lower relative humidity were having higher refractivity gradient values compared to the ones with higher relative humidity. As a result, the Figure exhibits a kind of undulating display. The monthly estimated refractivity gradient values were actually higher in the months of November down to March which happens to be the months with lower values of relative humidity as well as reduced rainfall and drops progressively between the months April to October and this happens to be the months with higher values of relative humidity as well as increased rainfall. This again is an affirmation the results of [23-25] and some other studies, that relative humidity have a direct proportionality with rainfall. The obtained monthly estimated refractivity gradient values for 2018 range from $-20.00 \mathrm{~N}$-units $/ \mathrm{km}$ to $-190.00 \mathrm{~N}$-units $/ \mathrm{km}$ with an average value of $-60.67 \mathrm{~N}$-units $/ \mathrm{km}$. These results are in conformity with the results of $[4,6,7,10]$.

Table 2. Monthly estimated refractivity gradient for 2018

\begin{tabular}{cc}
\hline Month & Estimated Refractivity gradient $(\mathrm{N}-$-units/km) \\
\hline January & -190.00 \\
February & -28.00 \\
March & -65.00 \\
April & -40.00 \\
May & -30.00 \\
June & -65.00 \\
July & -70.00 \\
August & -72.00 \\
September & -68.00 \\
October & -30.00 \\
November & -20.00 \\
December & -50.00 \\
Mean & 60.67 \\
\hline
\end{tabular}

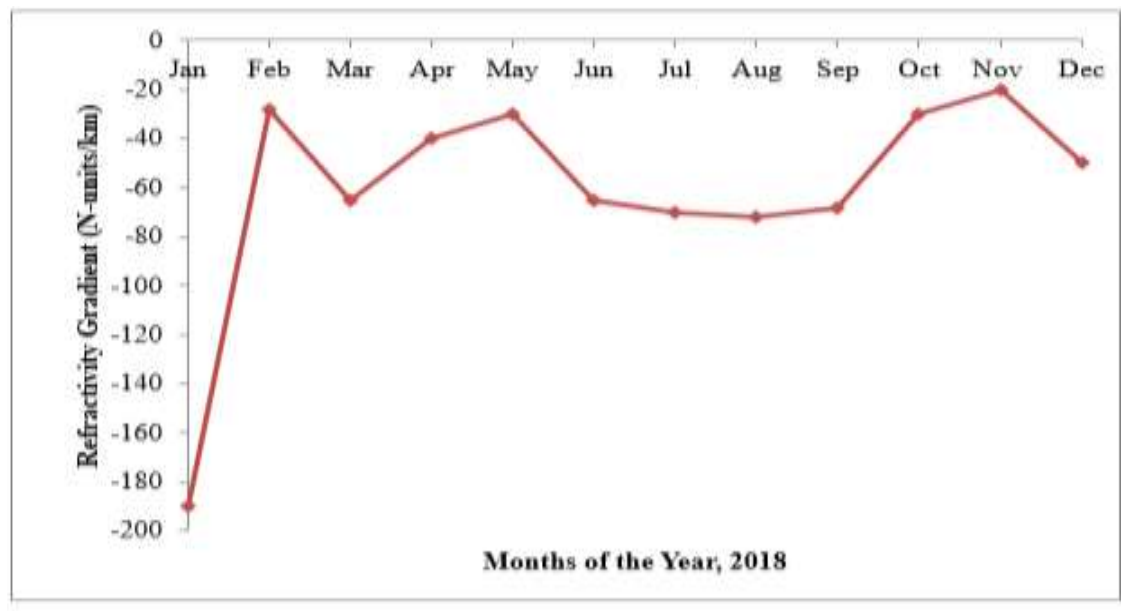

Figure 2. Monthly variations of refractivity gradient 
Figure 3 shows the plot of the average monthly measured air temperature against the monthly estimated refractivity gradient values for 2018. Figure 4 shows the plot of the monthly average measured relative humidity against the monthly estimated refractivity gradient values for 2018. While, Figure 5 shows the plot of the monthly average measured atmospheric pressure against the monthly estimated refractivity gradient values for 2018. It was observed that these measured essential climate variables were having significant influences on the monthly estimated refractivity gradient values for 2018. These effects were more noticeable during the months with high relative humidity values compared with the months with lower relative humidity values.

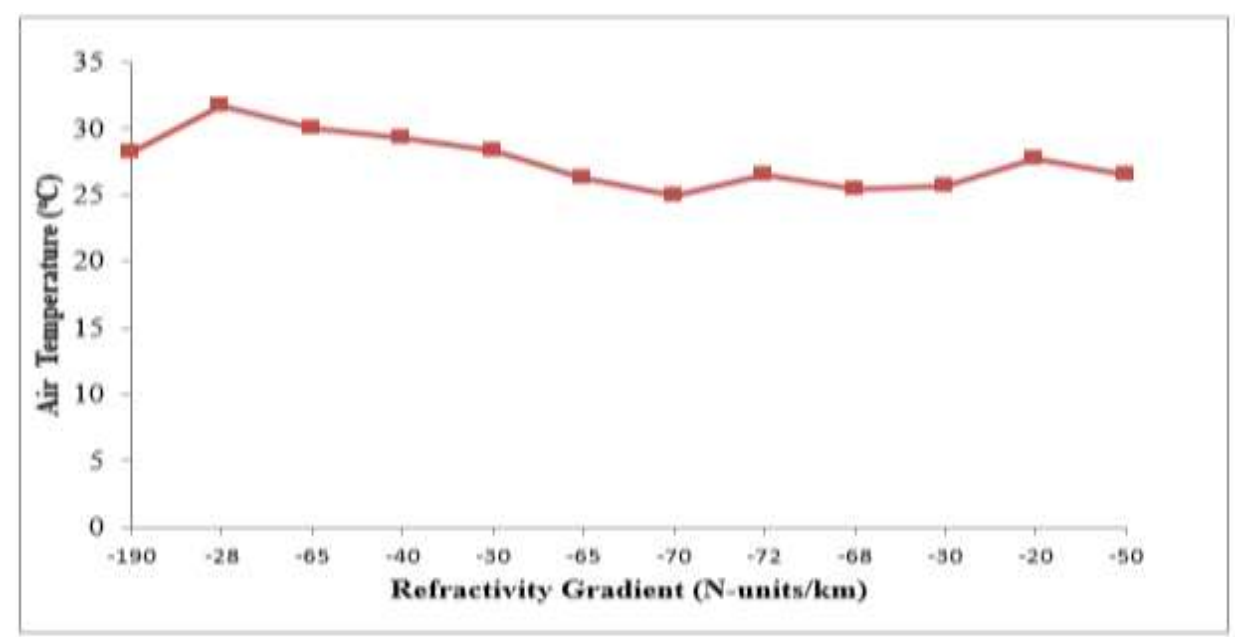

Figure 3 . The plot of the average monthly measured air temperature against the monthly estimated refractivity gradient values for 2018

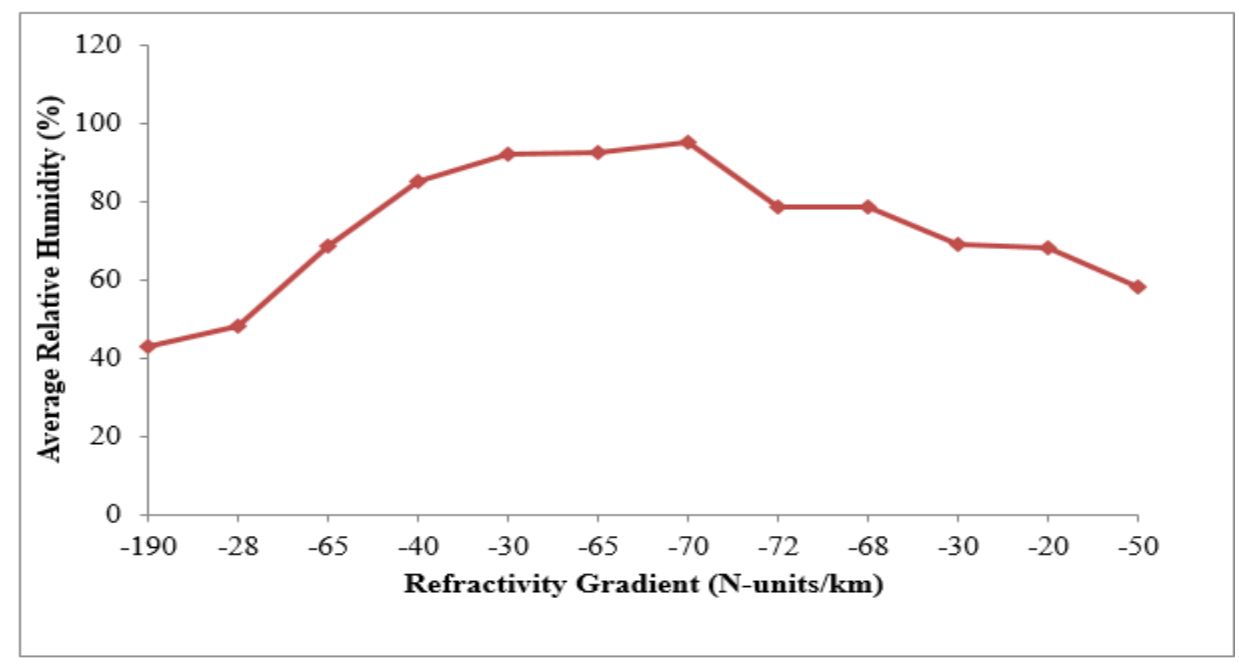

Figure 4 . The plot of the average monthly measured relative humanidity against the monthly estimated refractivity gradient values for 2018 


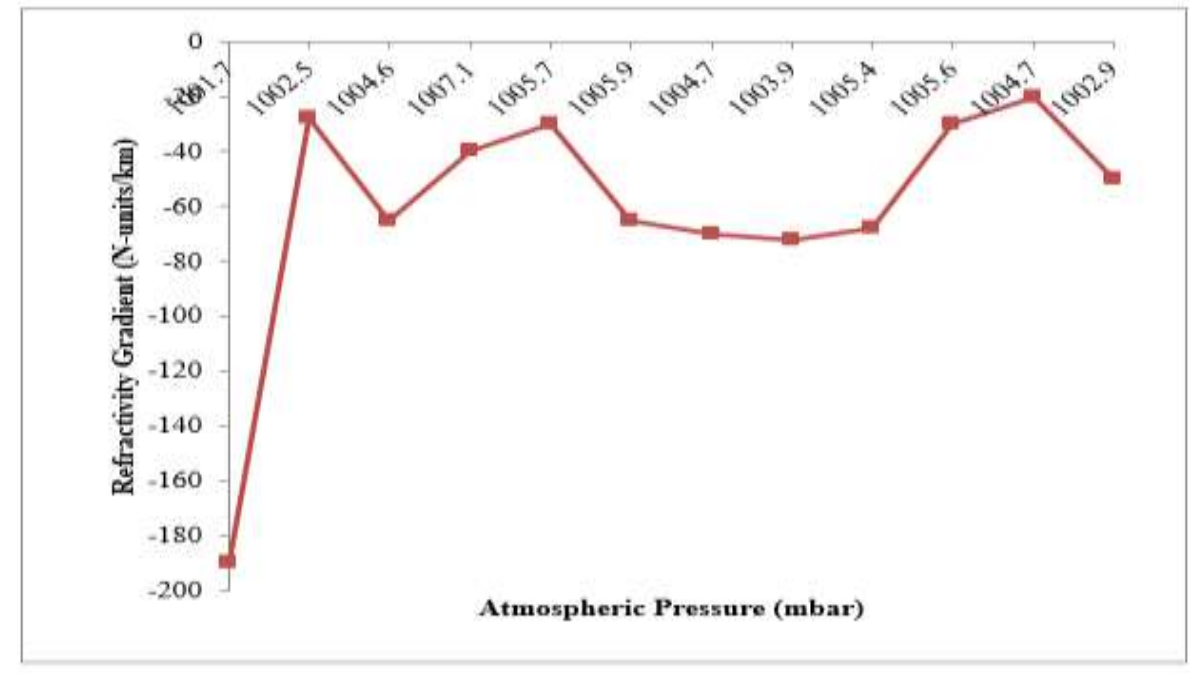

Figure 5. The plot of the average monthly measured atmospheric pressure against the monthly estimated refractivity gradient values for 2018

\section{CONCLUSION}

This study demonstrates the measurements of some essential climate variables at the administrative building of Edo University Iyamho-Auchi, Edo State, South-South, Nigeria with an elevation of about $188 \mathrm{~m}$ height above sea level using a self-implemented inexpensive portable metrological device by placing the device on a fixed position for continuous measurements so as to estimate the refractivity gradient which will be useful in prediction of the local radio wave propagation. It was observed that the months with low relative humidity values when having higher refractivity gradient values compared to the ones with higher relative humidity. It was also observed that the average monthly measured essential climate variables were having significant influences on the average monthly estimated refractivity gradient all through the period under consideration. These results obtained from this study would assistance in the enhancement of local radio signals.

\section{REFERENCES}

[1] Ukhurebor, K.E. and Odesanya I., "Relationship between Meteorological Variables and Effective Earth Radius Factor over Auchi, Edo State, South-South, Nigeria," Covenant Journal of Physical \& Life Sciences, vol. 7, no. 1. Pp. 1-10. 2019

[2] Ukhurebor, K.E., Azi, S.O., Abiodun, I.C. and Ojiemudia, S.E., "The Influence of Weather Variables on Atmospheric Refractivity over Auchi, South-South, Nigeria," Journal for Applied Science and Environmental Management, vol. 22, no, 4, pp. 471-475, 2018.

[3] Ukhurebor, K.E. and Azi, S.O., "Review of Methodology to Obtain Parameters for Radio Wave Propagation at Low Altitudes from Meteorological Data: New Results for Auchi Area in Edo State, Nigeria," Journal of King Saud University - Science, vol. 31, no. 4, pp. 1445-1451, 2019.

[4] Adediji, A.T., Ajewole, M.O. and Falodun, S.E., "Distribution of Radio Refractivity Gradient and Effective Earth Radius Factor (k-factor) over Akure, South Western Nigeria," Journal for Atmospheric and Solar-Terrestrial Physics, vol. 73, pp. 2300-2304. 2011

[5] Afullo, T.J., Motsoela, T. and Molotsi, D.F., "Refractivity Gradient and k-factor in Botswana," Radio Africa, pp. 107-110, 1999.

[6] Agbo, G.A., Okoro, O.N. and Amechi, A.O., “Atmospheric Refractivity over Abuja, Nigeria," International Research Journal of Pure and Applied Physics, vol. 1, no. 1, pp. 37-45, 2013.

[7] Ayantunji, B.G., Okeke, P.N. and Urama, J.O., "Diurnal and Seasonal Variation of Surface Refractivity over Nigeria," Progress in Electromagnetics Research, vol. 30, pp. 201-222, 2011.

[8] Bean, B.R. and Dutton, E.J., "Radio Meteorology," Dover Publication Co., New York, 259-273. 1968

[9] Brussaard, G. and Watson, P.A., "Atmospheric Modelling and Millimetre Wave Propagation," Chapman and Hall, 1995

[10] Falodun, S.E. and Ajewole, M.O., "Radio Refractive Index in the Lowest $100 \mathrm{~m}$ Layer of the Troposphere in Akure, South Western Nigeria," Journal of Atmospheric and Solar-Terrestrial Physics, vol. 68, pp. 236-243, 2006.

[11] International Telecommunications Union Recommendation, ITU-R, "The Refractive Index: Its Formula and Refractivity Data," Radiowave Propagation, ITU-R P-Series, No. 453-11, pp. 1-25, 2015, [Online] Available, http://www.itu.int/publ/R-REC/en. 
[12] Kolawole, L.B., "Vertical Profiles of Radio Refractivity over Nigeria," Journal of West African Science Association, vol. 26, pp. 41-60, 1981.

[13] Korak-Shaha, P.N. "The Physics of the Earth and its Atmosphere," John and Sons Inc., New York, USA, 2003.

[14] Martin, G. and Vaclav, K., "Atmospheric Refraction and Propagation in Lower Troposphere," Electromagnetic Waves, Prof. Vitaliy Zhurbenko (Ed.) 2011. ISBN: 978-953-307-304-0

[15] Ukhurebor, K.E. and Umukoro, O.J., "Influence of Meteorological Variables on UHF Radio Signal: Recent Findings for EBS, Benin City, South-South, Nigeria," IOP Conference Series: Earth \& Environment Science, vol. 173, no. 1, 2018.

[16] Ukhurebor, K.E., Olayinka, S.A., Nwankwo, W. and Alhasan, C., "Evaluation of the Effects of some Weather Variables on UHF and VHF Receivers within Benin City, South-South Region of Nigeria," Journal of Physics: IOP Conference Series, no. 1299, pp. 1-10, 2019.

[17] Alam, I., Mufti, N., Shah, S.A.A. and Yaqoob, M., "The Effect of Refractivity on Propagation at UHF and VHF Frequencies," International Journal of Antennas and Propagation, pp 1-8, 2016.

[18] Nwankwo, N. and Ukhurebor, K.E., "Investigating the Performance of Point to Multipoint Microwave Connectivity across Undulating Landscape during Rainfall," Journal of the Nigerian Society of Physical Sciences, vol. 1, no. 3, pp. 103-115, 2019.

[19] Bagiorgas, H.S., Assimakopoulos, M.N., Patentalaki1, A., Konofaos, N., Matthopoulos, D.P. and Mihalakakou, G., "The Design, Installation and Operation of a Fully Computerized, Automatic Weather Station for High Quality Meteorological Measurements," Fresenius Environmental Bulletin, vol. 16, no. 8, pp. 948-962. 2007

[20] Ji, H. H., Yong, H.K., Hyo, H.I., Na, Y.K., Sangjin, S. and Yourim Y., "Error Correction of Meteorological Data Obtained with Mini-AWSs Based on Machine Learning," Advances in Meteorology, pp. 1-8, 2018.

[21] Ukhurebor, K.E., Abiodun, I.C., Azi, S.O., Otete, I. and Obogai, L.E., "A Cost-Effective Weather Monitoring Device," Archives of Current Research International, vol. 7, no. 4, pp. 1-9, 2017.

[22] Ojeifo, M.O. and Akhimien, F.O., "Pattern of Fencing and Impacts in Urban Auchi, Edo State, Nigeria," International Journal of Physical and Human Geography, vol. 1, no. 1, pp. 26-34, 2013.

[23] Ukhurebor K.E., Abiodun I.C. and Bakare F., "Relationship between Relative Humidity and the Dew Point Temperature in Benin City, Nigeria," Journal for Applied Science and Environmental Management, vol. 21, no. 5, pp. 953-956, 2017.

[24] Ukhurebor K.E., Azi S.O., Abiodun I.C. and Enoyoze E., "Approximation of the Dew Point Temperature Using a Cost-Effective Weather Monitoring System,” Physical Science International Journal, vol. 14, no. 3, pp. 1-6. 2017

[25] Ukhurebor K.E., Batubo T.B., Abiodun I.C. and Enoyoze E., "The Influence of Air Temperature on the Dew Point Temperature in Benin City, Nigeria. Journal for Applied Science and Environmental Management, vol. 21, no. 4, pp. 657-660, 2017.

\section{BIOGRAPHIES OF AUTHORS}

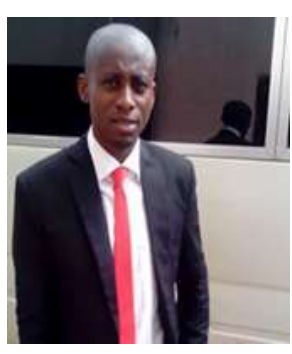

Kingsley Eghonghon Ukhurebor is a Lecturer/Researcher in the Department of Physics, Edo University Iyamho, Edo State, Nigeria. He completed his B.Sc. degree in Applied Physics/Geophysics from the Ambrose Alli University, Ekpoma, Edo State, M.Sc. degree in Physics/Electronics and Ph.D. in Physics/Electronics from the University of Benin, Benin City, Nigeria where he worked on measurements and analysis of some meteorological variables. He also earned a Post Graduate Diploma in Education from the Usmanu Danfodiyo University, Sokoto, Nigeria. He is a Research Fellow of the West African Science Service Center on Climate Change and Adapted Land Use (WASCAL), Competence Center, Ouagadougou, Burkina Faso. He is a member several learned academic organizations. His research interests are Climatic/Environmental/Telecommunication Physics. He is an editor and reviewer to several reputable journals. He has authored and co-authored several national and international research publications, conference articles, and books.

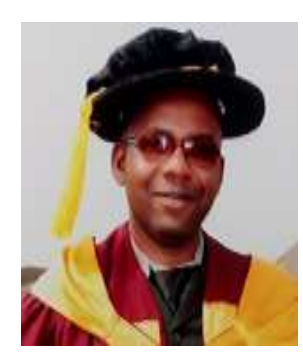

Wilson Nwankwo holds a Ph.D. in Information Technology, an M.Sc. in Computer Science, an MBA, a B.Sc. in Business Computing and a LLB in Law. He is currently an Associate Professor in Software Engineering/Cyber Security at Edo University Iyamho Nigeria. Dr Nwankwo is a core industry expert and prior to joining the academic career train, he spent over 17 years in strategic management capacities and on ICT Projects in reputable organizations. He is an active member of learned professional societies including: Nigeria Computer Society; Computer Professionals Registration Council of Nigeria; Project Management Institute; Information Systems Audit \& Control Association (ISACA); Institute of Electrical \& Electronic Engineers; Institute of Software Practitioners of Nigeria to name a few. His research interests are: Intelligent Enterprise Systems, Soft Computing, Artificial Intelligence, Analytics Embedded Systems, Wireless Networks and High Availability Data Systems. 